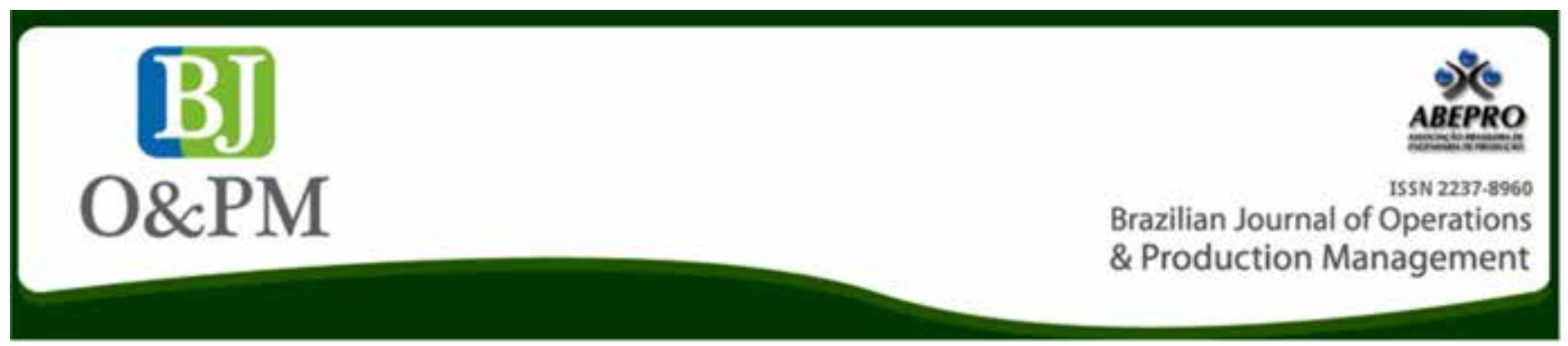

\title{
MAKERSPACE FOR SKILLS DEVELOPMENT IN THE INDUSTRY 4.0 ERA
}

Eduardo Ferro dos Santos eduardo.ferro@usp.br University of São Paulo - USP, Lorena, São Paulo, Brazil.

\section{Paul Benneworth}

paul.benneworth@hvl.no Western Norway University of Applied Sciences, Bergen Norway. University of Twente, Enschede, Netherlands.

\begin{abstract}
Goal / Purpose: Universities are increasingly investing in makerspaces. These learning spaces are presented as a place where students can share their projects, can innovate using rapid prototyping equipment, use low and high technology that serves as a starting point for students to launch start-ups, get advice on how to place a product in the market, and relate to potential lenders. This paper aims to discuss whether companies can benefit from these projects and whether skills for engineers can be developed in this environment. The paper provides insightful perceptions of the actions developed by one emergent university to develop innovative methodologies to support industry and students, to provide potential partnerships that fund projects in order to better prepare professionals for the industry 4.0 .
\end{abstract}

Design / Methodology / Approach: A discussion of the subject was carried out based on the existing literature and an exploratory study in an existing makerspace in the Netherlands. It was one qualitative research based on a case study. Field observation and research questions were based on the technical skills of engineering described in theory.

Results: This article presented the idea that the makerspaces can be a great source of innovation if they are appropriately designed. The connection between universities and companies, aligned to active methodologies for teaching and learning meets a global need within a corporate universe to get faster and simpler and make the team see the project in a more holistic and complete manner. However, the goal is to bridge the gap with professors, researchers, makers, start-ups, and companies who want to use business-to-business practices. It can be said that these are beneficial characteristics of a makerspace observed: (i) students' learning is more active, (ii) more interaction between students and professors, through different areas (iii) at an early stage, students get in contact with the professional reality of their field, as the projects are related to real Engineering problems, and (iv) students develop transversal skills.

Practical implications: This paper identifies the potential that Makerspaces offer as a strategic approach to teaching and learning related to the fourth industrial era. This paper implies that universities and academics that wish to tailor their education to industry 4.0 need understand this model better, and where appropriate invest in educational infrastructures such as this in universities, companies or cities. This will ensure that universities are educating professionals with the most suitable skills for industry and society, generating innovation in creative teaching and learning spaces.

Research Limitations: The study is limited to one empirical research, analysis, and observation of a case study that can serve as a basis for future studies in other locations.

Keywords: University-Industry Relationship; Makerspace; Skills for Engineers. 
Brazilian Journal of Operations \& Production Management

Volume 16, Número 2, 2019, pp. 303-315

DOI: 10.14488/BJOPM.2019.v16.n2.a11

\section{INTRODUCTION}

Each era of industrial evolution is innovative, requiring new skills from the professionals involved (Gray, 2012). Technological development has shattered old work models, requiring professionals that are even more skilled. Industry 4.0 has changed the professions and the way they are learned, with an impact on teaching and learning methodologies (BRICS Skill Development Working Group, 2016). Companies question how one learns in universities and proposes methods on how the next generations should learn (Schuh et al., 2015). The market has been invaded by digital technology and the use of these technologies by all ages is requested.

New technologies in manufacturing and prototyping processes, such as 3D printers, laser cutting machines, and computer numerical control machines (CNC) have accelerated growth in recent years. This growth can be traced through to the emergence and development of low cost electronics and programming technologies, such as Arduino and Raspberry, and the increasing use of free software, allowing new spaces for teaching and learning, which are referred to as "Makerspaces" (Farritor, 2017). Makerspaces are prototyping and digital manufacturing environments that integrate machines, devices, and enable creativity, stimulating collaborative innovation and new business development (Andersson, 2014). Makerspaces, Digital Manufacturing Labs, Fablabs, and Hackerspaces are some of the various terms used to describe these communities and, although they may differ in terms of their precise balance of activities, the degree of involvement of partners and the objectives, there are similarities between all these forms (Costa and Vieira Pelegrini, 2017).

In these environments, participants are expected to use these devices independently, encouraging peer learning and knowledge sharing, providing dynamic interactions for experimentation, education, research, and production among participants (Kohtala, 2017). Makerspaces are becoming increasingly popular features of Universities and other educational institutions, and the idea has even extended out into cities, with Makerspaces open to the public (Farritor, 2017). The term "makers" applies to "hands-on" projects using creativity and innovation to start a business activity or develop products, either new or improved, driven by Project-Based Learning (Fordyce et al., 2015). These spaces offer an environment that stimulates creativity and innovation, with various low-cost equipment installed, to facilitate participants (students, entrepreneurs, the public and even companies) to create new products or develop their projects and prototypes. In addition to providing access to technologies and tools, they also foster knowledge sharing and creation of synergies, focusing on creativity and innovation (Graves, 2014).
As well as the infrastructural dimension of makerspaces, they also offer a human capital dimension, creating empathic, collaborative, creative professionals who are always searching for problem-solving and innovation, something increasingly important in the context of the knowledge economy (Horvath and Cameron, 2015). This paper considers the extent to which makerspaces can potentially assist university-company integration by attuning future engineers with future needs for competencies in product development, innovation, and communications. Addressing that question requires understanding the learning practices stimulated within a makerspace and how they allow companies to attune students' needs with their business needs. That then in turn allows a specification and identification of the contributions that makerspaces make to these learning processes; therefore, in this paper, we ask the question in terms of how makerspaces can contribute to educating empathic, collaborative and creative professionals oriented towards problem solving and innovation. More directly, what do the practices of a makerspace bring to companies?

A case study is presented from one such makerspace, the example of Designlab in the Netherlands, which is an experiment in stimulating the development of these new softer skills for professional engineers. It was possible identify the critical elements of the maker space that correspond to the development of these softer skills and reflect on the way that they function to support these heterogeneous maker teams. To conclude, a model is proposed for the term "maker ecosystems", in which activities support four separate layers, infrastructure, organizations, people, and finances, and reflect upon the potential conceptual and policy applications of this model to improve the development of transversal skills amongst engineering students.

\section{THE MAKER MOVEMENT}

Makerspaces hold collective activities that seek the construction and diffusion of alternative forms of innovation and collaboration, rooted in the thinking of the Maker Movement (Halverson and Sheridan, 2014). The maker movement is an extension of the DIY (Do It Yourself) culture based on practices of creating, building, modifying, and repairing something using traditional or digital tools and machines (Taylor, 2016). Projects may be developed on virtual platforms through peer-to-peer production or in physical spaces (Costa and Vieira Pelegrini, 2017). What Makerspaces have in common is that they are social spaces, with open workshops providing various tools and equipment enabling the individual or collaborative projects where people with different skills can collaborate and learn from each other around projects of shared interest (Taylor, 2016). These come in a range of flavors including: 
Digital Manufacturing Laboratories: spaces installed in formal or strongly connected educational environments, usually linked to a specific university department involved in research, development, teaching, or production of models (Celani, 2012).

Hackerspaces: these spaces comprise the people interested in electronics and programming functioning, as community labs, following hacker and maker practices; these participants, spaces, and communities are of increasing interest because they offer areas for interactions between people and computing technologies (Toombs, 2017).

Fablabs are technical prototyping platforms for learning, invention, and innovation, presenting basic requirements, such as opening space for the community in part of the time, active participation in the Fablabs network and sharing of knowledge, archives, and documentation (Costa and Vieira Pelegrini, 2017). The idea emerged in order to develop entrepreneurship locally, sometimes adopted in schools as platforms for Project-Based Learning, or PBL (Määttä and Troxler, 2011); they are connected to a global community of students, educators, technicians, researchers, and others interested in sharing network knowledge (Mostert-Van Der Sar et al., 2013).

Makerspaces are generally spaces led by institutions, users, profit-driven projects, and local, non-profit economic development with a focus on social problems. They can be typologized based on projects that determine the objectives of the laboratories and the profile of the users. This strand moves toward the solution of problems through educational practices, including the use of active methodologies focused on real cases of improvement of processes, projects, products, and societal problems, such as Project-Based Learning (Prince, 2004), Work-Based Learning (Morris and Blaney, 2013), Industry Based Learning (Henschke and Poppins, 2009), P5BL - Problem-, Project-, Product-, Process-, People-Based Learning (Fruchter and Lewis, 2001), or Learning By Doing (Schank, 1995). These are teaching and learning methodologies that seek perceptions, and practices for the development of students' competence in industry, services, and society, with students using these places as a laboratory for further promoting their skills and learning. These spaces can also boost local development, generating a shared space where universities, companies, and society can develop their ideas and test their products, while at the same time acquiring knowledge and qualification to the necessary methods and techniques.

\section{The entrepreneurial maker movement}

The maker movement can be associated with direct economic benefits to companies either directly through the developments of new products and services, or more indirectly, by infusing these companies with new connections, networks, and practices, assisting them to access the resources necessary for innovation (Böhmer et al., 2015). Different elements of the maker movement have focused upon and sought to emphasize different processes through which these benefits are realised, whether through the creation of start-ups or the resolution of problems. Both processes seek to develop new products and services but face different contextual limitations and barriers. Start-ups seek to create a first product or service and their industrialization (Tötterman and Sten, 2005), while the already consolidated companies are focused on people management and innovation (Tether and Tajar, 2008). Recent technological changes have reduced the sunk capital costs for the creation of many new start-ups in terms of their purchase of hardware, software and operational infrastructure (Calcagnini et al., 2016), with cheap computers, low-cost software and information, and resources freely available via the internet, which, at the same time, can provide a gateway to access new markets (Internet Society, 2015). Likewise, co-working spaces offer access to complementary professional services required for start-up and assist with building new entrepreneurial networks.

One of the benefits of a prototyping environment is that it enhances the investment case for a new business. They allow applications, products or services to be tested and validated for the market, seeking visibility and feasibility for potential investors (Fordyce et al., 2015). In effect, the maker movement offers a complimentary business development skill for new start-ups in terms of achieving proofof-concept and prototyping without the need for costly investments that might need unhelpful changes to business plans. In the contemporary environment, there are many free or low-cost digital tools and software packages suitable for low-cost hardware that are adequate for working on new ideas, projects or solve problems (Prototyping, 2014). Makerspaces provide access to CNC machines and 3D printers for carrying out the production of the prototypes, drawing upon other members' knowledge resources. New electronic components based on programmable cards, such as Arduino (D'Ausilio, 2012), easily adaptable with low-cost sensors, facilitate the creation of connected products. Many opensource shared project databases simplify the first steps. The maker movement shares many documents, ideas, and projects that are accessible through the internet (Halverson and Sheridan, 2014).

Once the first product or service is created, Makerspaces might also provide a second round of support by assisting with the preparations for launch. Platforms such as Kickstarter (2018) or Catarse (Aveni and Pinto, 2014) allow open dialogues about the new project, establishing a community and enabling the financing of pre-sales. Industrializing and 
Brazilian Journal of Operations \& Production Management

Volume 16, Número 2, 2019, pp. 303-315

DOI: 10.14488/BJOPM.2019.v16.n2.a11 scaling a project remains difficult in the Makerspace context. Although there are Cloud manufacturing services dedicated to manufacturing small and medium-sized runs, industrializing a prototype is still a challenge (Tao et al., 2011), and the production of packaging, transportation, and after-sale care remains tricky, depending upon the 'maker' themselves to establish a supply chain, partners, distributors, etc. Makerspaces may assist where they are embedded into an institutional context that can offer the necessary enterprise support, whether an innovative business or a university. Makerspaces are therefore places where new kinds of creativity and inventions are brought together with complementary skills in community projects; they offer a great potential if coupled to educational institutions to provide learning sites for students for the new kinds of skills in demand in the $21^{\text {st }}$ century.

\section{The skills current required}

Teaching and learning methodologies that seek to develop students' competencies, perceptions, and practices in the industry, services, and society, transform these makerspaces, as in the case of laboratories, further promoting their skills and their learning. These spaces may boost local development, generating a shared space where universities, companies, and society can develop their ideas and test their products, while at the same time pooling and sharing knowledge and qualification to the necessary methods and techniques (Fordyce et al., 2015). This mirrors the contemporary need amongst enterprises for professionals who can deploy their professional skills to address an extended and diversified set of problems that require different skills (Caten et al., 2019; Chhikara et al., 2013), thus mobilizing knowledge, methods, and skills in a variety of industrial and service activities.

Universities seek to deliver professionals who have teamwork skills (Marzo Navarro et al., 2006). However, at the same time, it is recognized that the primary focus of universities is aimed to educate students with their technical skills necessary for a particular profession or occupation, rather than equipping people with transversal competencies relevant for different activities, contexts of professions (Harrison and Turok, 2017). With transversal skills, it is possible to think about competencies, such as leadership, entrepreneurship, teamwork, creativity, interpersonal relationships, critical thinking, problem solving, among many others (Hernandez-Linares et al., 2015). Some institutions stand out for implementing methodologies that promote student interaction around real work situations and teamwork, in order to promote integration skills, responsibility, teamwork, communication, expression skills, and leadership (Barraycoa and Lasaga Millet, 2010). Developing transversal competences leads to the need to transcend traditional teaching models and apply active learning methodologies (UNESCO, 2010). In this context, project-based learning focuses on interdisciplinary teamwork for problem-solving, articulating theory and practice during the execution of an open project, that is, without a single solution, which allows the combination of development of technical and cross-cutting skills (Kolmos et al., 2009).

Thus, project-based learning is also understood as a strategy for innovation and employability (Kolmos and Holgaard, 2010), insofar as its characteristics allow students to interact with problems related to the professional context. These problems are significant if they are based on real business or societal problems and developed in interaction with commercial or social users, allowing students to benefit from the opportunity to experience an application environment with different professionals, gaining application experience, developing and exploring engineering skills, having University professors and company professionals as facilitators and supervisors of this process (Hawkins et al., 2013).

The competencies developed in this type of environment will contribute to reinforcing students understanding of theory by simultaneously developing entrepreneurial attitudes, initiative, and innovation skills, thus making the learning process more meaningful, motivating and challenging for students and professors (Santos et al., 2015). These competencies are in line with those required by engineers for the future, such as strong analytical skills, leadership, creativity, communication skills, business and management skills, professionalism, and ethical standards, dynamism, agility, resilience, and flexibility (Caten et al., 2019).

The maker movement can be considered as a perspective on personal and professional development, stimulating a different way of looking at the world and connecting with it through a more autonomous and agile approach, less rule-bound, with more flexibility, global positioning, and more innovative thinking (Halverson and Sheridan, 2014). It goes beyond culture change, directly addressing how teams manage and develop projects, and has recently become increasingly attractive to companies as a way of connecting to qualified people who can contribute to improving and innovating their products, production system and processes. The opportunity for interaction with students and their professors can help renew industry professionals with new ideas, concepts, and knowledge. For those activities embedded in universities, it provides industry with opportunities to assist the university in defining professional profiles closer to industry's real needs, contributing to the development of professionals with employability skills more in line with their needs (Böhmer et al., 2015). Therefore this issue can help link the university to businesses through the creation of these maker communities that spanning business and educational worlds. 


\section{New engineers}

This approach is also useful for universities for the education of engineers well attuned to the needs of contemporary society, able to deal with constant challenges to competitiveness in a global context (Murti, 2014). University courses find themselves wrestling with the dual challenge of dealing with the high speed of technological changes, demanding changes to their core technical curriculum, along with the previously alluded to need for transversal skills (Albulescu et al., 2014). Makerspaces offer the potential to help universities address these points by providing them with infrastructure and techniques to ensure that their students learn these transversal skills by applying this latest technical knowledge to collaborative application contexts. Traditional engineering education generally follows an engineering training perspective using deductive teaching, with themes illustrated through mathematical models introduced by professors in the classroom; students' skills are tested by examinations and tests with little emphasis on the fundamental practical real problems faced by the profession for which these students are being prepared (Santos et al., 2018b).

Engineering Education develops in parallel with the demands and advice of industry and other stakeholders regarding the desired knowledge, skills and attitudes of future engineers (Crawley et al., 2008; Nadae and Carvalho, 2017). $A$ recent global initiative has been developing the CDIO (Conceiving-Designing-Implementing-Operating) initiative, starting from updating engineering education with the belief that every graduate engineer should be able to: Design-Implement-Operate complex engineering products, processes, and systems. According to the CDIO Council, an engineer must be able to work in modern team-based environments where they will be responsible for executing a sequence of tasks to design and implement a product, process or system within an organization. The CDIO's focuses on critical thinking and creative methods and learning management (personal and professional skills and attributes), teamwork and communication (interpersonal skills), and designing, implementing, and operating systems in a real world engineering context (Gray, 2012). It makes transversal competencies critically important, particularly around project management, teamwork, personal development and communications skills (Caten et al., 2019; Webb, 1995).

Therefore, what is absent from traditional engineering undergraduate courses that are preparing students for engineering practice? (Mills and Treagust, 2003). There a range of possible criticisms, whether an excessive focus on scientific and technical knowledge to the neglect of practice, the absence of project experiences to develop communication skills and teamwork, a lack of attention for the real world (economy, legislation of the environment), and even a lack of practical knowledge by lecturers, underpinned by academic promotion systems that privilege publishing over actual experience (Santos et al., 2018a). Makerspaces therefore seem to offer one potential opportunity to address these criticisms, promoting the development in learning spaces and extra class activities, individual or group, characterizing an active environment where student creativity is one crucial ingredient that regulates the dynamic of growth. The interdisciplinary projects of a Makerspace effectively contribute to student learning. This type of knowledge consists of a methodology that emphasizes teamwork, the resolution of interdisciplinary problems and the articulation of theory and practice, in the accomplishment of a project that ends with the presentation of a solution or product from a real situation related to the future professional context (Böhmer et al., 2015; Farritor, 2017).

\section{A STRATEGIC MAKERSPACE: THE DESIGNLAB CASE AT UNIVERSITY OF TWENTE}

To examine the practical function of a Makerspace, we now turn to consider the initiative of Designlab, at the University of Twente (UT), Enschede, The Netherlands (Eggink, 2015). The University of Twente is a technological university in the East of the Netherlands, which, in 2010, relaunched its slogan as "high tech, human touch," replacing its previous slogan "the entrepreneurial university". The combination of high tech and human touch has become one of the spearheads of the future, in order to capitalize upon the universities' unique position as what it self-describes as 'dual-core university', with both a strong science and engineering faculty, and a social sciences faculty (Designlab, 2018). Within that, the university has developed a Makerspace called "Designlab" with the mission to integrate the expertise of both academic cores within the mission "science2design4society". This has the intention of ensuring that design knowledge is used to make new technologies available for users and that, together with the latest insights in humanities and business, these are used to tackle problems in contemporary society (Eggink, 2015).

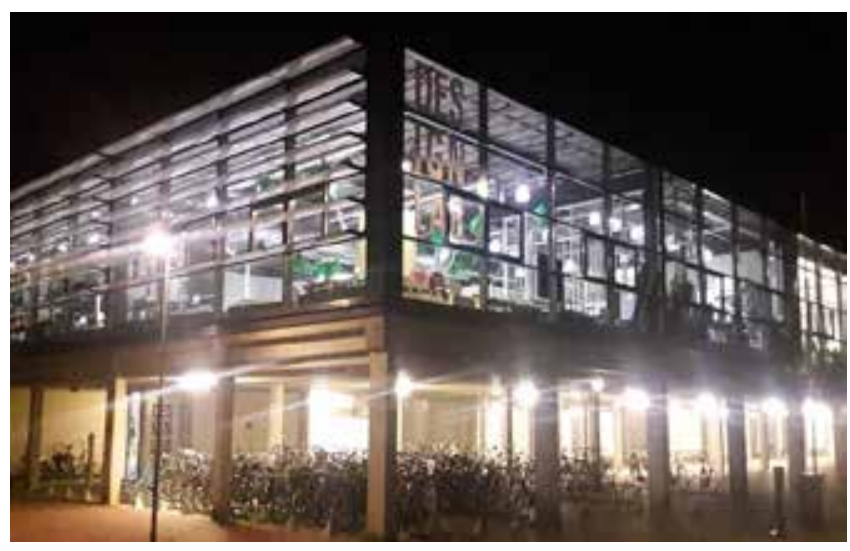

Figure 1. Designlab entrance 
This initiative is dedicated to introducing specific teaching, and research teams focused on creating a creative culture, "where the scientific results of technologies can collide and connect with the real-world challenges that people face today. The Designlab design process "science2design4society" follows five phases; namely Briefing and Analysis, Ideation, Conceptualization, Prototyping, and Exhibiting/ Communicating. The physical layout of the makerspace is linked to this process flow, with spaces available in the building that can be used for these unique elements in an optimal way, with the idea that these spaces will be used as a design problem goes back and forth through different stages of the entire process. The process starts with a briefing at the entrance, through to closed classrooms for ideation and conceptualization, workshops for the prototype and then back to the exhibition area in the foyer for presenting the solution to the outside world.

\section{DESIGNLAB STRUCTURE}

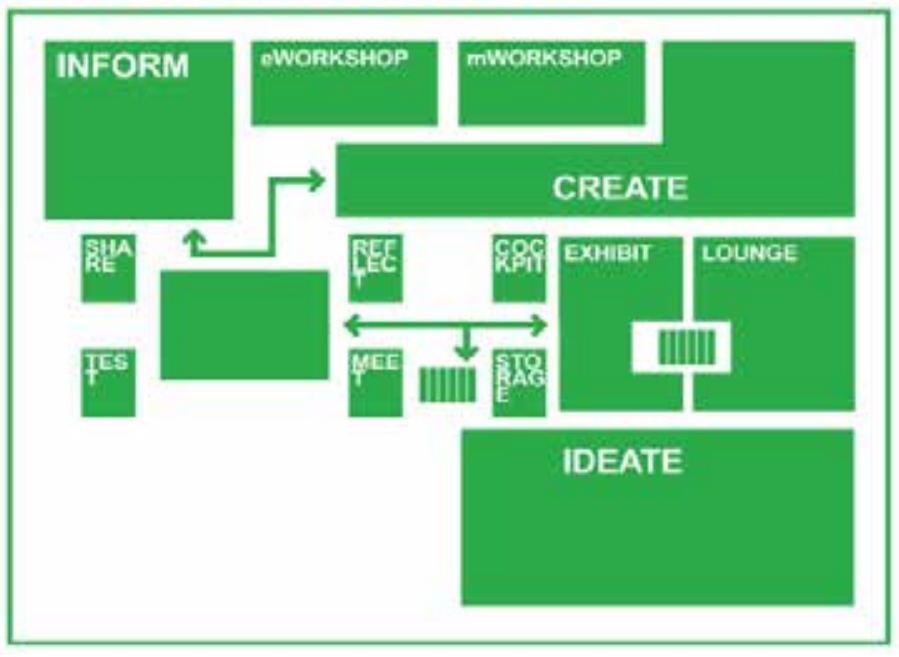

Figure 2. Designlab structure

The Designlab is open during its office hours to academics as well as students, start-ups, other companies, and government, with the intention of becoming a creative meeting place that has been designed for science and society to interact in ways that better stimulate those interactions.

In the 2016/2017 academic year, Designlab hosted activities from 55 different educational modules; it contributed to the development of some research programmes and actively that interacted with 28 external partners. Designlab hosted 114 events, linking the University of Twente and the society, including Pioneers of Health Care, Pitch and Match, the Entrepreneurial Challenge, Global Goals Jam and the Smart Cities Pre-conference with cities and universities in Enschede, Palo Alto, Linköping, Münster, Dalian, and Heidelberg. There were 339 research-related activities around DesignLab, with around 1000 students to use the workshop facilities; a number of student start-ups were facilitated; DesignLab supported a number of flagship university projects, such as the University Innovation Fellows (students working on a shared project of interest to university leaders), Smart Living Campus (using the campus as a testbed for new technological ideas), and the Ethics of Drones projects. Thirty-two researchers were recruited as DesignLab Fellows, and a substantial amount of social media activity took place, with 1400 followers on Facebook, Twitter, and Instagram, attracting some $20 \mathrm{~K}$ website page-views.

In this study, the skills and attitudes that Designlab sought to develop are evaluated by following the protocol "Formulation in Evaluating the Technical Skills of Engineering" (Yusoff et al., 2012). This protocol allows for the assessment of the transversal skills that are necessary for contemporary engineering programmes to meet with the needs of users. The key elements of this protocol are presented below.

It is important to emphasize that this is a descriptive, exploratory research paper that describes the technical composition of the facilities and contributions to the development of competences, introducing an exploration on the subject. The protocol used for the study was derived from the Formulation in Evaluating Technical Skills of Engineering (Yusoff et al., 2012). The methodology was based on a real-world situation and a practical approach in which participants were asked whether they had acquired a range of skills, as follows (Yusoff et al., 2012):

- Procedure: It was a qualitative research using an exploratory, descriptive approach, based on a case study. The students were exposed to the process under analysis through experiments carried out in their projects.

- Participants: Five different Makerspace users were interviewed through structured questions. They were selected based on the study level, not being of the same category.

- Sources of data and analysis: Data were collected during site visits. The lead author acted as an interviewer and observer.

- Research questions to interviewees: They were based on the skills described in the Formulation for Evaluating Engineering Technical Skills.

The protocol was applied through direct interviews with five different Designlab users: representing one of each university staff, undergraduate student, master's student, one doctoral student, and one professor. These interviewees also reflected on how DesignLab had helped them to develop those skills. It provides the basis for an exploratory reflec- 


\begin{tabular}{|c|c|}
\hline Skills & Criteria \\
\hline Communication skills & $\begin{array}{l}\text { Speak in clear sentences; give clear direction; listen and ask the question; present ideas confidently and effectively; under- } \\
\text { stand and speak English and other languages }\end{array}$ \\
\hline Teamwork & $\begin{array}{l}\text { Function effectively as an individual, understand the role in a group; function effectively in a group as a team member; accept } \\
\text { and provide feedback in a constructive and considerate manner (forming, storming, performing, adjourning); work in a group } \\
\text { with the capacity to be a leader. }\end{array}$ \\
\hline Lifelong learning & $\begin{array}{l}\text { Recognize the need to undertake lifelong learning; possess and acquire the capacity to undertake lifelong learning; engage in } \\
\text { lifelong learning; set their learning targets; plan in achieving their learning goal(s) }\end{array}$ \\
\hline Professionalism & $\begin{array}{l}\text { Understand the social responsibilities (human factors and social issues); understand the cultural and global responsibilities (aware- } \\
\text { ness on cultural and nature surroundings); understand the environmental liabilities (aware of environmental needs); commit to } \\
\text { professional responsibilities (be licensed as an engineer); commit to ethical responsibilities (be accountable for their actions) }\end{array}$ \\
\hline $\begin{array}{l}\text { Problem-solving and } \\
\text { decision-making skills }\end{array}$ & $\begin{array}{l}\text { Undertake problem identification (identify a problem in a work place); implement problem-solving (use experiences to solve } \\
\text { problem); apply formulation and solution (use science, mathematics or technology to solve problem); be creative and innova- } \\
\text { tive and see different points of view in solving issues; identify the root cause of the problems. }\end{array}$ \\
\hline Competency & $\begin{array}{l}\text { Use the necessary techniques of engineering practice; use the skills required for engineering practice; use modern engineering } \\
\text { tools and software; work toward quality standards and specifications; assemble equipment following written directions. }\end{array}$ \\
\hline $\begin{array}{l}\text { Knowledge of science } \\
\text { and engineering } \\
\text { principles }\end{array}$ & $\begin{array}{l}\text { Continue to acquire knowledge of sciences and engineering fundamentals; apply the knowledge of engineering } \\
\text { fundamentals; select and use proper tools and equipment for particular job/task; access, analyze and apply skills } \\
\text { and knowledge of science and engineering; understand the principles of sustainable design and development. }\end{array}$ \\
\hline $\begin{array}{l}\text { Knowledge of contem- } \\
\text { porary issues }\end{array}$ & $\begin{array}{l}\text { Continue learning independently in the acquisition of new knowledge, skills and technologies; use information } \\
\text { technologies (computers, networks and electronic); use communication technologies in the knowledge-based } \\
\text { era; use computing technologies, read newspaper }\end{array}$ \\
\hline $\begin{array}{l}\text { Engineering system } \\
\text { approach }\end{array}$ & $\begin{array}{l}\text { Utilize a systems approach to design operational performance; utilize a systems approach to evaluate operation- } \\
\text { al performance; design systematically; analyze engineering design; demonstrate knowledge and understanding. }\end{array}$ \\
\hline $\begin{array}{l}\text { Competent in a } \\
\text { specific engineering } \\
\text { discipline }\end{array}$ & $\begin{array}{l}\text { Continue acquiring in-depth technical competence in a particular engineering discipline (electrical, highway, } \\
\text { structure, etc); apply technical skills in a specific engineering discipline effectively; design and conduct experi- } \\
\text { ments; analyze and interpret data; apply knowledge in multidisciplinary engineering. }\end{array}$ \\
\hline
\end{tabular}

Table 1. Formulation in Evaluating Technical Skills of Engineering (Yusoff et al., 2012)

tion on whether those users associated with DesignLab are oriented towards these transversal skills. For these, the understanding of each of the skills and criteria was questioned, based on the matrix of answers (see table 2 below):

Table 2. Matrix of answers developed by authors

\begin{tabular}{c|c|c}
\hline Grade & Name & Description \\
\hline 0 & No skills & I know nothing about this \\
\hline 1 & $\begin{array}{c}\text { Some } \\
\text { knowledge }\end{array}$ & $\begin{array}{c}\text { I know something about this, and after } \\
\text { some further reading or instruction I can } \\
\text { perform simple tasks }\end{array}$ \\
\hline 2 & $\begin{array}{c}\text { Working } \\
\text { knowledge }\end{array}$ & $\begin{array}{c}\text { Good } \\
\text { I can perform daily tasks }\end{array}$ \\
\hline 4 & Expertency & $\begin{array}{c}\text { I know a lot about the subject. If the } \\
\text { competency is a part of the solution the } \\
\text { team is building, this would be the author } \\
\text { or co-author }\end{array}$ \\
\hline
\end{tabular}

Each of the interviews was used to generate a score for each of the items in the protocol and the database from this analysis is presented below. The focus group comprised five DesignLab's users (students or professionals) directly associated with the University of Twente. The participants' names will be kept classified and herein they will be identified as their course "B.Sc. - Graduation", "M.Sc. - Master", "Ph.D. Doctorate", and their position "Prof - Professor". The script for the focus group was based in skills discussion (Yusoff et al., 2012). Additionally, a statistic treatment was done by skills, such as "average", "standard deviation", and "coefficient of variation" (Hammersley, 2013).

Perhaps unsurprisingly the levels of skills grow according to the level of educational development of the respondents; the skills are higher in professors and staff, who have already gone through the development of these skills, although the staffs are still university students. The significant variation is in Problem-solving and decision-making skills and Competency, which naturally develop at each educational stage. The best relationships are in Lifelong learning and Professionalism, which are practically essential attributes in UT students. Highlight should be given to the fact that the DesignLab brings together participants with a range of experience to work together on various shared projects to stimulate social learning processes in which people acquire these transversal skills as they participate in the community. In the next section, are considered the various coupling repertoires by which this community is held together to allow this social learning to take place.

\section{RESULTS AND DISCUSSION}

It is possible to argue that makerspaces appear to offer the opportunity for the mobilization of different communities in which participants vary along two characteristics, the 
Table 3. Answers from the interviewed individuals

\begin{tabular}{|c|c|c|c|c|c|c|c|c|}
\hline Skills & B.Sc. & M.Sc & Ph.D & Staff & Prof. & Average & $\begin{array}{l}\text { Standard } \\
\text { deviation }\end{array}$ & $\begin{array}{c}\text { Coefficient of } \\
\text { variation }\end{array}$ \\
\hline Communication skills & 3,0 & 4,0 & 5,0 & 5,0 & 5,0 & 4,4 & 0,9 & 0,2 \\
\hline Teamwork & 4,0 & 4,0 & 5,0 & 5,0 & 5,0 & 4,6 & 0,5 & 0,1 \\
\hline Lifelong learning & 5,0 & 5,0 & 5,0 & 5,0 & 5,0 & 5,0 & 0,0 & 0,0 \\
\hline Professionalism & 5,0 & 5,0 & 5,0 & 5,0 & 5,0 & 5,0 & 0,0 & 0,0 \\
\hline Problem solving and decision making skills & 3,0 & 3,0 & 4,0 & 5,0 & 5,0 & 4,0 & 1,0 & 0,3 \\
\hline Competency & 3,0 & 3,0 & 4,0 & 5,0 & 5,0 & 4,0 & 1,0 & 0,3 \\
\hline Knowledge of science and engineering principles & 3,0 & 4,0 & 4,0 & 5,0 & 5,0 & 4,2 & 0,8 & 0,2 \\
\hline Knowledge of contemporary issues & 3,0 & 4,0 & 4,0 & 5,0 & 5,0 & 4,2 & 0,8 & 0,2 \\
\hline Engineering system approach & 3,0 & 4,0 & 5,0 & 5,0 & 5,0 & 4,4 & 0,9 & 0,2 \\
\hline Competent in specific engineering discipline & 3,0 & 4,0 & 5,0 & 5,0 & 5,0 & 4,4 & 0,9 & 0,2 \\
\hline
\end{tabular}

expertise that they have in these transversal competencies, along with the scope and freedom they have in their occupation to exercise creativity and agency in these makerspaces. The findings relating to seniority versus transversal skills suggest that there is a clear trade-off, with the most active members of the community, those being with the weakest transversal skills (the students). The makerspace potentially provides a range of infrastructures and forms of organizational technique that couple these heterogeneous actors together in ways that allow these social learning processes and, by exploring these dynamics in more detail, it is possible to get a better understanding of the micro-practices, by which makerspaces could potentially contribute to improving the learning experience for $21^{\text {st }}$ century engineers through the development of this transversal competence set. Therefore, in this section, the other element of our analysis considers how DesignLab could potentially contribute to the development of those skills.

\section{Communication skills}

The basis for the DesignLab model is that every project operates through the proposal of submissions that are the basis for a set of constructive discussions, which, in turn, help to shape and set the boundaries of the following step in this process. The ideas are discussed in models based and adapted from Design Thinking (Brown and Rowe, 2008) and Canvas (Hanshaw et al., 2015) and stimulate the development of communications skills amongst participants. Part of what foregrounds the issue of communications appears to be the role played by the flow and the transformation of ideas. As an idea flows through this "science2design4society" process, it is necessary to transfer the knowledge in various ways, to take it and prepare it for the following stage, from Briefing, Analysis, Ideation, Conceptualizing, Prototyping, and Exhibiting. There is a materiality to each transformation because of the need to physically move from one space to another, to present and situate the new idea within the original context and to gain feedback. Most area is arranged to facilitate teamwork and to allow quick circular iterations between the different stages.

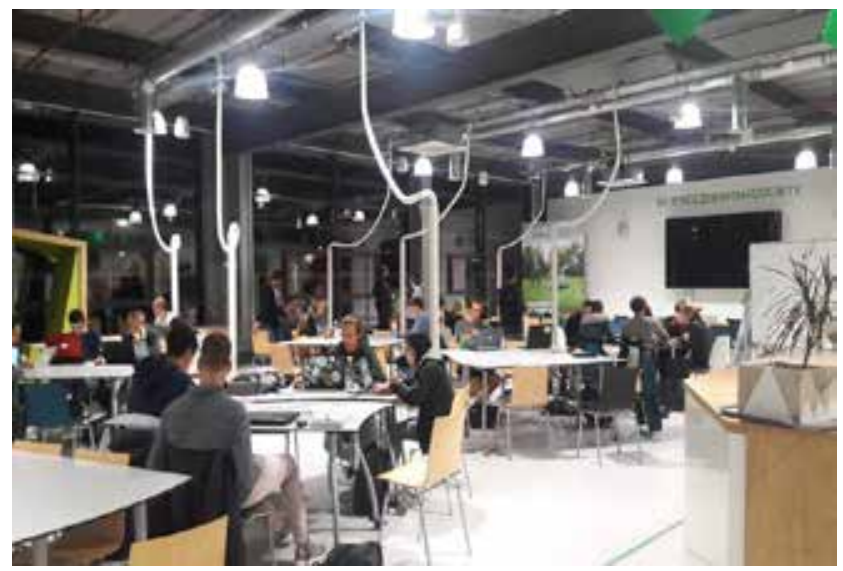

Figure 3. Activities in groups at Desiglab

\section{Lifelong Learning}

It is precisely within the context above of PBL and CDIO that activities favor and stimulate the adoption of other active learning methodologies with the aim to integrate exact sciences and technology with social and human sciences, as well as personal and interpersonal skills, through interdisciplinary connections. The University of Twente has designed and implemented a significant curriculum innovation in all its bachelor programmes since 2013, the Twente Education Model (TOM after the Dutch Twents Onderwijsmodel). The university has been developing the concept of Student-Driven Learning, as comprising many of the elements underlying TOM (Visscher-Voerman and Muller, 2017). TOM consists of a pre-defined curriculum structure of modules of 15 European Credits (ECTS) per module; all modules have a project, in which educators use a more extensive variety in innovative learning and assessment methods. The current challenges for professors are how to give students more control over their learning process, how to decrease the number of summative assessments and how to increase the number of for- 
mative feedback moments. The formulation and testing of hypotheses, survey of the electronic literature and experiments in each project are developed in Designlab. Student theses and dissertations are also produced at Designlab.

\section{Teamwork}

DesignLab's activities address problem identification and formulation by modelling, estimating, analysing and recommending solutions. For each project, case activities are carried out in groups where participants contribute to the discussion and ultimate resolution of the projects. There is some individual work necessary, as in the case of masters and doctoral degrees that are completed by a defense of an individually completed thesis, but every bachelor module is based primarily on team-based learning.

\section{Professionalism}

The concept of "high tech human touch" is related to a holistic perspective of the understanding of social responsibilities, spanning human life, the environment, as well as better integration between the university and its most immediate societal partners. This is featured in the concept "science2design4society". A significant emphasis is given to hands-on experimentation, something that is recognized in the work-credits that ensure that students are rewarded for their external activities as well as their lab-based efforts.

\section{Problem-solving and decision-making skills}

DesignLab works with planned activities, such as lectures, symposia, research meetings, and project result presentations. These are also related activities in which DesignLab conducts multidisciplinary projects with many stakeholders from the beginning (briefing in the 'Inform') to the end (presentation in 'Exhibit'). DesignLab users are mainly students, who use the space to do the final work. The interviewed users were very positive regarding the laboratory's open atmosphere, the possibilities of adjusting the project to their needs and the fact that all the facilities meet their expectations.

\section{Competency}

All the skills of good engineers are explored in one project, across a range of areas. Tools and techniques of engineering practices are used, and the method of free software is also stimulated. Workshops related to the use of software (drawing, electronics, mathematics), using the skills necessary for engineering practice. There is modern equipment for their use, such as 3D printers, CNC machines, laser cutting, programming kits, and robotics.

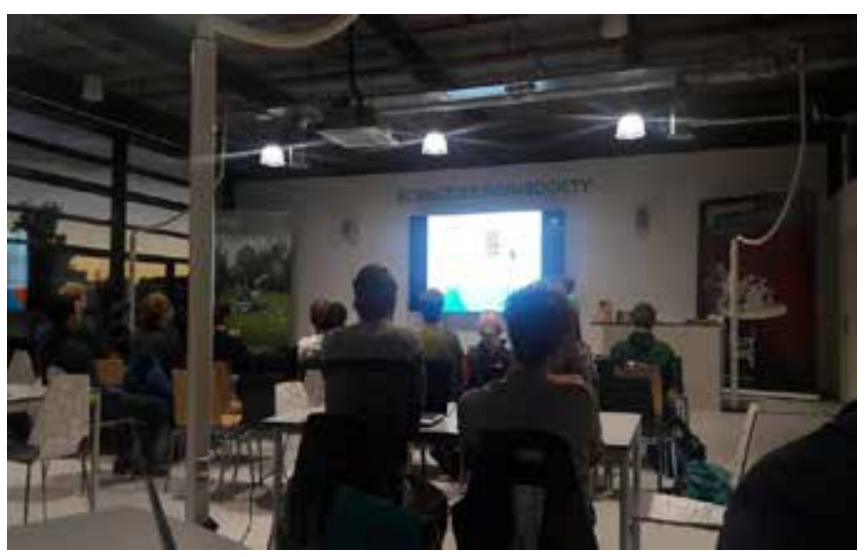

Figure 4. Workshop at Desiglab

\section{Knowledge of science and engineering principles}

The DesignLab infrastructure also offers the opportunity to work on basic sciences. Moreover, the principles of design and sustainable development are present at UT. There are projects that encompass the UN's sustainable development goals (Colglazier, 2015). The UT also has a team willing to guide these projects (BMS, 2018).

\section{Knowledge of contemporary issues}

The use of Designlab is open to all. The acquisition of cogeneration independently is also stimulated, giving access to information technologies (Computers, networks and electronics). Students have access to socialization, and indeed socialization is one of the main things the lab has to offer. Many courses and workshops are organized regularly in the various rooms of DesignLab, from full teaching sessions to shorter seminars and brief explanations available from the DesignLab team members.

\section{Engineering system approach}

There is a project team available at all times. The furniture objects in low-poly style were then mixed with standard project tables, whiteboards and chairs to make a complete interior. The designed furniture objects included a 'design-island' (in analogy with a cooking island) for doing design work in a group, a little 'house' to work individually and in a concentrated way, and a pitch module with integrated stand for doing on-site presentations. A bigger team of students constructed the unique furniture. 
Brazilian Journal of Operations \& Production Management

Volume 16, Número 2, 2019, pp. 303-315

DOI: 10.14488/BJOPM.2019.v16.n2.a11

\section{Competent in a specific engineering discipline}

Students can go deeper into their projects to gain indepth technical competence in a particular engineering discipline, whatever it may be. It is possible to design and conduct experiments, and analyze and interpret data, and apply knowledge in engineering and multidisciplinary areas.

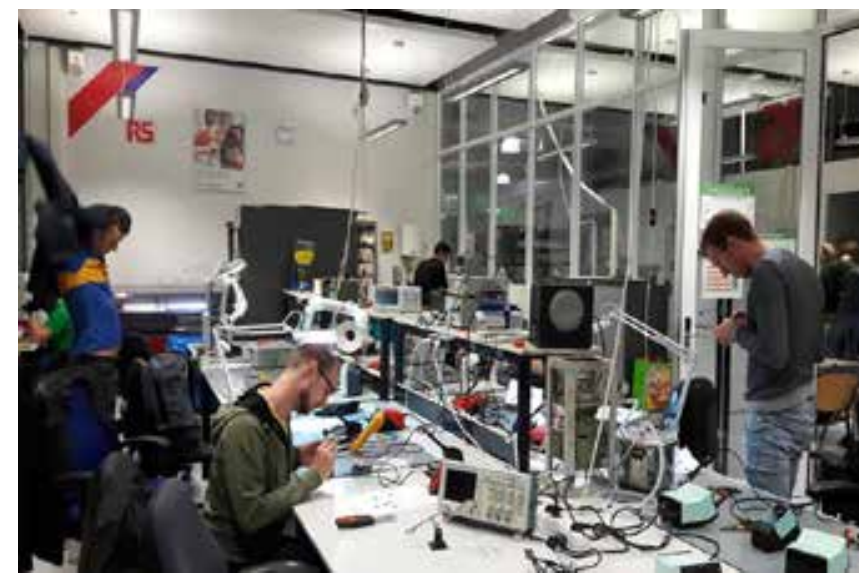

Figure 5. Specific subjects being developed at Desiglab

\section{CONCLUSION}

This article presented the idea that the makerspaces can be a great source of innovation if they are appropriately designed. They should promote skills development, innovation, and product development. It is particularly relevant to ensure the coupling of a heterogeneous community of creative users together in ways that they meet different users' needs while incorporating the reality of real problems, integrated with society and companies. However, at the same time, it creates various tensions for the participants in holding these diverse interests, goals, and needs together to achieve these different aims; thus, whilst a makerspace, built by an engineering faculty, could be more innovative if it allowed the use of space by engineering students (and non-engineering students) from problems brought by participants, at the same time it may require a different funding structure (company support) or a different physical location to allow it to function effectively without disrupting the other core educational activities.

Makerspaces create connections between practical makers, with universities and companies, and which creates or at least can create - a mutual benefit. The relationship meets a global need within business to more quickly access complex knowledge, while professors, researchers, makers, start-ups, and companies can all use these business-to-business practices to support their missions. Therefore, there is a potential for the maker movement (and the dissemination of new digital manufacturing technologies more generally) to enable new scenarios for education, research and for the development, production, and distribution of products. Manufacturing labs hosted at universities can potentially foster interaction between researchers, students, and society by opening new dimensions to science and education, inspiring curiosity and providing new ways to develop ideas with a specific impact. Corporate laboratories, in addition to providing ongoing training for employees, have the potential to create new products quickly and inexpensively and to potentiate open innovations.

At the same time, what is observed is that achieving these benefits in the educational context is not a straightforward process because it requires the creation and the maintenance of a sustainable ecosystem bridging between very different actors. Four important "layers" are identified within this ecosystem, and the main contribution of this paper is proposing a more general model. An active maker space has organized a range of activities that effectively bind four layers of an innovation ecosystem together to allow these different teams to function in a sustainable and rewarding (educational, profitable, creative) manner. The four layers proposed are:

- Infrastructures: the technologies (hardware, software, applications) that allow makers to undertake projects

- Organizations: businesses and universities that permit participation in makerspaces within the various organizational processes

- People: makers who are motivated to operate in these heterogeneous team environments to create outputs that serve their ends

- Finance: the resources to allow these various activities to take place and to be realized in a sustainable way

In the context of an illustrative paper based on a single case study, it is necessary to be modest about the wider generalizability of our findings; however, at the same time, it is possible to see that the various individual projects and activities were methods for integrating these four layers to create active maker ecosystems. It is possible to propose that this idea of the multi-layered maker ecosystem is a potentially fruitful avenue of further exploration and development, both for theory and practice. Through this proposal, it will enable a maker movement to materialize ideas through prototypes, being a more valuable way of deepening, communicating and validating an idea. In this work, it is perceived that a makerspace is a vital path and a key opportunity for an entrepreneurial university, integrating the base of innovation and entrepreneurship. Future research could extend 
this by identifying how these spaces can stimulate regional development. This impact includes the observation of the effect of spaces in universities as well as the use by the society to which it belongs. In examining the impact that spaces have on the region, it is possible to stimulate new areas for companies and local society.

The result of this project are highly creative and enterprising professionals, better sensitized to the problems of industry 4.0 , society 5.0 and education 4.0 , and students with a better analytical and socioemotional capacity. This suggests that both a better understanding of this model is required, along with additional investments in makerspaces in universities, companies, and other urban places.

\section{Acknowledgments}

São Paulo Research Foundation (Fundação de Amparo à Pesquisa do Estado de São Paulo - FAPESP) for grant in Process 2018 / 02625-1

\section{REFERENCES}

Albulescu, V. L.; Litra, M.; Neagu, C. (2014), "The third mission of universities and some implications", UPB Scientific Bulletin, Series D: Mechanical Engineering, Vol. 76, No. 2, pp. 301-312.

Andersson, H. (2014), "Makerspace", Scandinavian Public Library Quarterly, Vol. 47, pp. 20-22.

Aveni, A.; Pinto, L. F. S. (2014), "Crowdfunding o modelo canvas do site Catarse", Revista Eletronica Gestão \& Saúde, Vol. 4, No. 3, pp. 3380-3396.

Barraycoa, J.; Lasaga Millet, O. (2010), "La competencia de trabajo en equipo: más allá del corta y pega", Vivat Academia, No. 111 , pp. 66-70.

Behavioural Management and Social Sciences Faculty BMS (2018). Sustainable Development Goals. Available from: $<$ https://www.utwente.nl/en/bms/sdg/\#sdg-and-prme>. Access: 14 Nov 2018.

Böhmer, A. I.; Beckmann, A.; Lindemann, U. (2015), (Open Innovation Ecosystem - Makerspaces within an Agile Innovation Process", The Proceedings of the ISPIM Innovation Summit: Changing the Innovation Landscape, No. Dec, pp. 1-11.

BRICS Skill Development Working Group (2016), Skill Development for Industry 4.0, Roland Berger, India.

Brown, T.; Rowe, P. G. (2008), "Design thinking", Harvard Business Review, Vol. 86, No. 6, pp. 252.

Calcagnini, G. et al. (2016), "The role of universities in the location of innovative start-ups", Journal of Technology Transfer, Vol. 41, No. 4, pp. 670-693.
Caten, C. S. T et al. (2019), "Reshaping engineering learning to promote innovative entrepreneurial behavior", Brazilian Journal of Operations \& Production Management, Vol. 16, No. 1, pp. 141-148.

Celani, G. (2012), "Digital Fabrication Laboratories: Pedagogy and Impacts on Architectural Education", Nexus Network Journal, Vol. 14, No. 3, pp. 469-482.

Chhikara, J. et al. (2013), "Professional skills", Computers and Security, Vol. 1, No. 3, pp. 249-251.

Colglazier, W. (2015), "Sustainable development agenda: 2030", Science, Vol. 349, No. 6252, pp. 1048-1050.

Costa, C. M. O. N. G.; Vieira Pelegrini, A. (2017), “O Design dos Makerspaces e dos Fablabs no Brasil um mapeamento preliminar", Design \& Tecnologia, Vol. 7, No. 13, pp. 57-66.

Crawley, E. F.; Brodeur, D. R.; Soderholm, D. H. (2008), "The education of future aeronautical engineers: Conceiving, designing, implementing and operating", Journal of Science Education and Technology, Vol. 17, No. 2, pp. 138-151.

D'Ausilio, A. (2012), "Arduino: A low-cost multipurpose lab equipment", Behavior Research Methods, Vol. 44, No. 2, pp. 305-313.

Designlab (2018), Home. Available from: <https://www.utwente.nl/en/designlab/>. Access: 5 Oct 2018.

Eggink, W. (2015), “Designlab, making space for doing design as a process", Proceedings of the 17th International Conference on Engeering and Product Design Education, E\&PDE 2015: Great Expectations: Design Teaching, Research \& Enterprise - Loughborough, United Kingdom, 3-4 Sept. 2015. Available from: <https://research.utwente.nl/en/publications/ designlab-making-space-for-doing-design-as-a-process>. Access: 2 Nov. 2018.

Farritor, S. (2017), "University-Based Makerspaces: A Source of Innovation", Technology \& Innovation, Vol. 19, No. 1, pp. 389-395.

Fordyce, R. et al. (2015), "3D printing and university makerspaces: Surveying countercultural communities in institutional settings", Digital Culture \& Education, Vol. 7, No. 2, pp. 192-205.

Fruchter, R.; Lewis, S. (2001), "Mentoring Models in an A/E/C Global Teamwork e-Learning Environment", Proceedings of the 2001 American Society for Engineering Education Annual Conference \& Exposition, 2001, American Society for Engineering Education.

Graves, C. (2014), "What Is a Makerspace?", Knowledge Quest, Vol. 42, No. 4, pp. 8-13.

Gray, P. J. (2012), “CDIO standards and quality assurance: from application to accreditation", International Journal of Quality Assurance in Engineering and Technology Education (IJQAETE), Vol. 2, No. 2, pp. 1-8. 
Brazilian Journal of Operations \& Production Management Volume 16, Número 2, 2019, pp. 303-315 DOI: 10.14488/BJOPM.2019.v16.n2.a11
Halverson, E. R.; Sheridan, K. (2014), "The Maker Movement in Education", Harvard Educational Review, Vol. 84, No. 4, pp. 495-504.

Hammersley, P. (2013), "Using statistics", Nurse Researcher, Vol. 11, No. 3, pp. 4-6.

Hanshaw, N; Osterwalder, A. (2015), "The business model canvas - why and how organizations around the world adopt it", Strategyzer, Zürich.

Harrison, J.; Turok, I. (2017), "Universities, knowledge and regional development", Regional Studies, Vol. 51, No. 7, pp. 977-981.

Hawkins, S. et al. (2013), "Student expectations of problem-based learning (PBL)", Medical Teacher, Vol. 35, No. 6.

Henschke, K.; Poppins, P. (2009), "Industry-based learning", In: Tatnall A., Visscher A., Finegan A., O'Mahony C. (eds) Evolution of Information Technology in Educational Management. ITEM 2008. IFIP - The International Federation for Information Processing, vol 292. Springer, Boston, MA.

Hernandez-Linares, R. et al. (2015), "Transversal Competences of University Students of Engineering", Croatian Journal of Education-Hrvatski Casopis Za Odgoj I Obrazovanje, Vol. 17, No. 2, pp. 383-409.

Horvath, J.; Cameron, R. (2015), "What's a Makerspace (or Hackerspace)?" In: Horvath, J.; Cameron, R. The New Shop Class: Getting Started with 3D Printing, Arduino, and Wearable Tech. pp. 59-71.

Internet Society (2015), "The internet of things: an overviewInternet of Things (IoT): an overview", Internet of Things (loT), 15 sept. Available from: <http://www.internetsociety. org/doc/iot-overview>. Access: 18 Apr 2019.

Kickstarter (2018), “Foreverspin Spinning Top - The World's Most Valuable Metal", ForeverSpin.com, Available from: <https://www.kickstarter.com/projects/foreverspin/foreverspin-spinning-top-the-worlds-most-valuable?ref=bj4wx4\&gclid= EAlalQobChMI9vLW6dHT3gIVUflRCh26pA4REAAYASAAEgJY8 _D_BwE>. Access: 14 Nov. 2018.

Kohtala, C. (2017), "Making "Making” Critical: How Sustainability is Constituted in Fab Lab Ideology", Design Journal, Vol. 20, No. 3, pp. 375-394.

Kolmos, A.; Graaff, E.; Du, X. (2009), "Diversity of PBL- PBL Learning Principles and Models", In: Du, X; Graaff, E.; Kolmos, A., Research on PBL Practice in Engineering Education, Brill | Sense, Rotterdam, pp. 9-21.

Määttä, A.; Troxler, P. (2011), “Developing open \& distributed tools for Fablab project documentation", CEUR Workshop Proceedings.

Marzo Navarro, M.; Pedraja Iglesias, M.; Rivera Torres, P. (2006), "Las competencias profesionales demandadas por las empresas: el caso de los ingenieros 1", Revista de Educación, Vol. 341, No. 1, pp. 643-661.
Mills, J. E., Treagust, D. F. (2003), “Engineering Education: Is problem-based or projectbased learning the answer?", Australasian Journal of Engineering Education, No. Jan., pp. 2-16.

Morris, C.; Blaney, D. (2013), “Work-based learning”. In: Professor Tim Swanwick (eds), Understanding Medical Education: Evidence, Theory and Practice, 2 ed, pp. 97-109, The Association for the Study of Medical Education.

Mostert-Van Der Sar, M. et al. (2013), "FabLabs in design education", Proceedings of the 15th International Conference on Engineering and Product Design Education: Design Education - Growing Our Future, EPDE 2013, pp. 629-634.

Murti, A. B. (2014), "Why Soft Skills Matter", The IUP Journal of Soft Skills, Vol. 8, No. 3, pp. 32-36.

Nadae, J.; Carvalho, M. M. (2017), “A knowledge management perspective of the project management office", Brazilian Journal of Operations \& Production Management, Vol. 14, No. 3, pp. 350.

Prince, M. (2004), "Does Active Learning Work? A Review of the Research", Journal of Engineering Education, Vol. 93, No. 3, pp. 223-231.

Prototyping, R. (2014), “3D printing -- Additive manufacturing: An introduction", Popular Plastics \& Packaging, Vol. 59, No. 8, pp. 58-64.

Santos, E. F. et al. (2018a), “Project Based Learning Applied to Technical Drawing", Creative Education, Vol. 9, pp. 479-496.

Santos, E. F. et al. (2018b), "Project Based Learning Applied to Technical Drawing" Creative Education, Vol. 9, No. 3, pp. 479-496.

Santos, E. F.; Silva, M. B.; Barreto, M. A. M. (2015), "Proposta de uma estratégia de ensino-aprendizagem na disciplina de desenho técnico utilizando software livre e metodologia baseada em projetos", In: Hattum-Janssen, N. et al. (Eds.), Proceedings of XVII th International Symposium on Project Approaches in Engineering Education - PAEE. Anais...San Sebastian: Aalborg University Press.

Schank, R. C. (1995), "What We Learn When We Learn by Doing", Technical Report, No. 60, Sciences-New York, No. 60, pp. 1-37.

Schuh, G. et al. (2015), "Promoting work-based learning through industry 4.0”, Procedia CIRP, Vol. 32, pp. 82-87.

Tao, F. et al. (2011), "Cloud Manufacturing”, Advanced Materials Research, Vol. 201-203, pp. 672-676.

Taylor, B. (2016), "Evaluating the Benefit of the Maker Movement in K-12 STEM Education", Electronic International Journal of Education, Arts, and Science (EIJEAS), Vol. 2.

Tether, B. S.; Tajar, A. (2008), "Beyond industry-university links: Sourcing knowledge for innovation from consultants, private research organisations and the public science-base", Research Policy, Vol. 37, No. 6-7, pp. 1079-1095. 
Toombs, A. L. (2017), “Hackerspace Tropes, Identities, and Community Values", Proceedings of the 2017 Conference on Designing Interactive Systems - DIS '17, pp. 1079-1091. Available from: <http://dl.acm.org/citation. cfm?doid=3064663.3064760>. Access: 19 Apr 2019.

Tötterman, H.; Sten, J. (2005), "Start-ups: Business incubation and social capital", International Small Business Journal, Vol. 23, No. 5, pp. 487-511.

United Nations Educational, Scientific and Cultural Organization - UNESCO (2010), Engineering : Issues Challenges and Opportunities for Development, UNESCO report.

Visscher-Voerman, J. I. A.; Muller, A. (2017), "Curriculum Development in Engineering Education: Evaluation and Re- sults of the Twente Education Model (TOM)", 45th SEFI Annual Conference 2017 - Centro Cultural e de Congressos de Angra do Heroísmo (CCCAH), Angra do Heroísmo, Terceira Island, Portugal, 18-21 Sept.

Webb, N. M. (1995), "Group Collaboration in Assessment: Multiple Objectives, Processes, and Outcomes", Educational Evaluation and Policy Analysis, Vol. 17, No. 2.

Yusoff, Y. M. et al. (2012), "Formulation in Evaluating the Technical Skills of Engineering Graduates", Procedia - Social and Behavioral Sciences, Vol. 60, pp. 493-499.

Received: 13 Dec 2018

Approved: 17 Mar 2019

DOI: 10.14488/BJOPM.2019.v16.n2.a11

How to cite: Santos, E. F.; Benneworth, P. (2019), "Makerspace for skills development in the industry 4.0 era", Brazilian Journal of Operations \& Production Management, Vol. 16, No. 2, pp. 303-315, available from: https:// bjopm.emnuvens.com.br/bjopm/article/view/667 (access year month day). 